lesen haben wollte. Man solle die Retorte auf eine etwa zollhohe Lage von Asche setzen, sie dann ringsum mit Sand überschütten, und ohne irgend welche Maassregeln die Destillation unternehmen. Ich habe nach dieser Anleitung die Rectification der Schwefelsäure zweimal ausgeführt, und namentlich in einer Quantität von 15 Pfund und in einer Retorte, wie sie fast nicht schlechter sein konnte, und habe mich gewundert über die Leichtigkeit und Ruhe, mit welcher die Destillation vor sich ging. Offenbar wirkt die Asche hier als schlechter Wärmeleiter, und vermittelt das Kochen der Säure von den Seiten her. Man hat seitdem mannigfache Hülfsmittel vorgeschlagen, und alle laufen auf einen besonderen, dazu eingerichteten Apparat hinaus, aber eine Hinweisung auf den erwähnten ganz einfachen Handgriff ist mir noch nicht zu Gesicht gekommen.

\title{
Indigo, ein Mittel zur Entdeckung von Trauben- und Fruchtzucker;
}

von

Dr. E. Mulder.

(Aus dem Hollïndischen von Dr. Johannes Müller in Berlin.)

Trauben- und Fruchtzucker besitzen die Eigenschaft bei Anwesenheit von Alkalien das Indigblau in Indigweiss zu verwandeln. Löst man eine der beiden Zuckersorten in Wasser auf, setzt man Indigo zu und darauf Pottasche oder Soda, so wird der Indigo, schneller noch durch Erwärmen, doch auch bei gewöhnlicher Temperatur in Indigweiss verwandelt, welches in Alkalien auflöslich ist. Dasselbe ist der Fall, wenn man statt Wasser Alkohol anwendet; nur setzt sich dann der Indigo nach der Verwandlung bei Zutritt der Luft nicht in amorphem, sondern in krystallisirtem Zustande ab, und geht die Verwandlung schneller von statten. Gebraucht man eine Auflösung von Indigo in Schwefelsäure und nicht 
Indigo in Pulver, dann besitzt man darin ein Mittel, um die geringsten Antheile Trauben- und Fruchtzucker aufzufinden.

Indessen muss bei Anwendung von Indigolösung in Schwefelsïure die Flüssigkeit alkalisch reagiren, wenn der Versuch gelingen soll. Die Indigolösung wird nicht allein leicht verwandelt, der Indigo wird auch oxydirt; durch Aetzkali oder Natron wird sie ganz oder theilweise zerlegt. Im ersteren Falle erhält die Auflösung eine gelbe Farbe, welche nach Sättigung mit einer Säure wieder blau wird, wenn die Auflösung nicht vorher erwärmt ist; im zweiten Falle besitzt die Auflösung eine grüne Farbe, welche selbst bei mässigem Kochen nicht verändert wird. Fügt man der Indigolösung in Ueberschuss kohlensaures Kali oder Natron hinzu, dann bleibt die blaue Farbe selbst nach dem Kochen fast unverändert.

Sowohl die grüne als blaue Lösung geben eine äusserst empfindliche Reaction auf Trauben- and Fruchtzucker. Die erste übertrifft die zweite an Empfindlichkeit, und doch geben wir letzterer den Vorzug. Beim Aufsuchen von Trauben- oder Fruchtzucker handelt es sich nicht um Körper, welche andere Körper leicht zerlegen. Dieses ist der Fall jedoch bei der grünen Indigolösung, weshalb sie minder als Reagens anf Traubenoder Fruchtzucker zu empfehlen ist, als die blaue. Als Beweís, dass dieses bei der blauen Auflösung nicht der Fall ist, möge der Umstand dienen, dass diese selbst rach längerem Kochen nicht im Stande ist, Rohrzucker za zerlegen; bringt man indess in die Auflösung eine Spur von Traubenzucker, so findet die Zerlegung unmittelbar darauf statt. Dagegen wird die grüne Auflösung durch Rohrzucker zerlegt.

Die Zerlegung einer Indigolösung durch Traubenoder Fruchtzucker, wenn diese alkalisch durch kohlensaure oder ätzende Alkalien gemacht ist, liefert viel Figenthümliches, weshalb wir dasselbe näher beschreiben wollen. 
Dazu ist zuerst nöthig, zu untersuchen, was aus der Indigolösung in Schwefelsïure wird, sobald kohlensaure Alkalien, z. B. kohlensaures Kali, zngesetzt werden. Es werden Indigo-schwefelsaures und unterschwefelsaures Kali gebildet, der Ueberschuss der Schwefelsäure gebunden an Kali; ferner ist die Auflösung alkalisch durch das kohlensaure Kali, welches sich in der Auflösung befindet. Indigo-schwefelsaures Kali ist bei gewöhnlicher Temperatur weder in einer Aufösung von schwefelsaurem, noch in einer von kohlensaurem Kali auflöslich; beim Erwürmen wird es theilweise gelöst, oder derartig in der Flüssigkeit zertheilt, dass es an Aufösung grenzt. Indigounterschwefelsaures Kali dagegen bleibt ganz in der Auflösung und kann durch Filtriren (bei gewöhnlicher Temperatur) von Indigo-schwefelsaurem Kali getrennt werden.

Verlangt man eine alkalische Lösung von Indigo, so muss man letatere anwenden. Man that dann wohl, wenn man Indigo nicht in englischer, sondern in rauchender Schwefelsäure auföst, wodurch unterschwefelsaurer Indigo gebildet wird. Nöthig ist es eben wohl nicht, da sowohl das indigschwefelsaure als unterschwefelsaure Kali eine fast eben so empfindliche Reaction auf Trauben- und Fruchtzucker giebt.

Man hat also in der Auflösung: Indig-unterschwefelsaures Kali und in der Auflösung vertheilt indig-schwefelsaures Kali, welches beim Erwärmen theilweise aufgelöst wird. Hiervon bringt man etwas in ein Reagensglas, fügt so viel Wasser bei als nöthig ist, um eine hellblaue Auflösung zu erhalten, und kocht dieselbe. Die Farbe bleibt dabei unverändert. Fügt man nun der gekochten Fliissigkeit eine äusserst geringe Menge einer wässerigen Lösung von Trauben- oder Fruchtzucker hinzu, so verändert sich die blaue Farbe durch's Grïne ins Purpurrothe; bei einer grösseren Menge Zucker verändert sich die purpurrothe Farbe langsam ins Rothe und nacher ins Gelbe. Schüttelt man die Flüssigkeit, so geht diese, 
falls sie eine purpurrothe Farbe hat, durch's Grine ins Blaue; hat sie eine gelbe Farbe, so durchlïuft sie die obengenannten Earben von Gelb zum Grinblau oder Grün. Derselbe Versuch kann so oft wiederbolt werden, als noch Zucker und Indigo in der Auflösung sind. Lässt man die purpurrothe oder gelbe Auflösung einige Zeit stehen, dann durchliunft sie an der Oberfläche die Farbenreibe und entstehen im ersten grïne, im zweiten rothe und grïne Streifen nach unten.

Es wäre zu wünschen, dass man alle diese Farbenschattirungen in chemischen Formeln ausdrücken könnte, so wie eino Krklärung übor die vielen Umsetzungen, welche bei dieser Reaction vorkommen, geben zu können.

Von dem Gedanken ausgehend, dass zwischen den verschieden gefärbten Zerlegungsproducten ein inniger Zusammenhang besteht, welche Berzelius aus indigschwefelsaurem Kali durch Winwirkung von Kalkwasser erhielt, und denjenigen, welche wir bei dieser Indigozuckerreaction wahrnehmen, haben wir diesen Zusammenhang wirklich gefunden. Indigschwefelsaures Kali kann mit kohlensaurem Kali gekocht werden, ohne dass sich die Farbe merklich verändert; doch bei längerem Kochen endigt es sich damit, dass die Flïssigkeit eine gelbe Farbe annimmt, wie bei der Zuckerreaction. Die gelbe Farbe ist einem entstehenden Zerlegungsproduct im Indigo, und zwar dernselben, welches Berzelius durch Einwirkung von Kalkwasser auf indigschwefelsaures Kali (freie Flavin-Schwefelsïure) erhalten hat, zuzuschreiben. Wir hoffen später auf diesen gelben Körper zurückzukommen; für die Reaction selbst ist es hinreichend, zu wissen, dass derselbe ohne Zucker bei Einwirkung von kohlensaurem Kali und indigschwefelsaurem Kali gebildet wird. Aber mit dem indigschwefelsauren Kali kann noch ein anderes Zersetzungsproduct gebildet werden, welches eine rothe Farbe besitzt (die Rufinschwefelsäure nach Berzelius). Die rothe Farbe geht der gelben voran, so dass die letzte aus der ersten gebildet wird. 
272 Mulder, Indigo zur Entdeckung von Traubenzucker etc.

Wenden wir diese Thatsachen auf die Reaction an. Kocht man die blaue Aufösung, dann wird durch Einwirkung von kohlensaurem Kali anf Indigoblau unmittelbar ein rother und wahrscheinlich theilweise daraus ein gelber Körper gebildet; dabei wird die Farbe wenig verändert, da beide nur in äusserst kleinen Mengen entstehen. Fügt man dann der Auflösung Traubenzucker bei, so wird das Indigoblau in Indigoweiss verwandelt und kommt die rothe Farbe zum Vorschein. Diese letztere hat deshalb mit der Zuckerreaction nichts zu schaffen.

Schüttelt man die Flüssigkeit, so wird das Indigoweiss in Indigoblau verändert und die Farbe scheint wenig verändert. Bei Wiederholung der Probe erhält man eine gelbe Aufösung, der rothe Körper wird in den gelben umgesetzt. Wird dann wieder geschüttelt, so fängt sie an, eine rothe, blaugrüne Farbe anzunehmen, während sie theilweise in Indigoweiss auf Augenblicke, wo selbes oxydirt wird, zu Indigoblau unter dem Einfluss von kohlensaurem Kali in den rothen Körper übergeht.

Die Aufösung muss sodann eine grüne Farbe besitzen, denn was einmal gelb ist, bleibt gelb, und gelb und blau geben grün, der rothe Körper wird dann ins Gelbe umgesetzt. Die rothe und grüne Farbe, die sich an der Oberfläche bilden, lassen sich aus dem Mitgetheilten genugsam erklären. Der Versuch kann also sehr oft bei Anwesenheit von Zucker wiederholt werden, wenn das kohlensaure Kali keinen Zucker zerlegte. Für die Zuckerprobe ist die Zerlegung von keinem Einfluss, im Gegentheil giebt sie der Reaction einige Farbe, die selbst dem Chemiker nicht gleichgültig ist. Doch wir wiederholen es nochmals, dass die schöne Farbenreihe mit der Reduction des Indigoblaues durch Zucker nichts gemein hat. 